\title{
Design and Analysis of Infrared Diffractive Optical Systems Using Beam Synthesis Propagation
}

\author{
Hyun Bae Kong ${ }^{1}$ and Doo Jin $\mathrm{Cho}^{2 \dagger}$ \\ ${ }^{1}$ LIG Nex1 Co., Ltd., 148-1, Mabuk-dong, Giheung-gu, Yongin 446-912, Korea \\ ${ }^{2}$ Department of Physics, Ajou University, San 5, Woncheon-dong, Yeongtong-gu, Suwon 443-749, Korea
}

(Received April 18, 2013; Revised manuscript July 19, 2013; Accepted July 22 2013)

\begin{abstract}
An F/1.2 infrared optical system that involves two aspheric BD-2 lenses and an aspheric diffractive surface was designed over $8-14 \mu \mathrm{m}$ with a field angle of $15.2^{\circ}$. The system may be used in uncooled cameras and is analyzed using beam synthesis propagation (BSP). The diffractive surface is modeled as a physical surface with a given thickness, and results are compared with those obtained by conventional methods, such as the exit-pupil method and a method which superposes diffraction orders.
\end{abstract}

Keywords: Diffractive optics, Aspheric optics, Infrared optics, Optical system design, Beam synthesis propagation

OCIS codes: (220.0220) Optical design and fabrication; (220.3620) Lens system design; (050.1965) Diffractive lenses; (050.1970) Diffractive optics

\section{회절광학을 이용한 적외선 광학계 설계 및 $\mathrm{BSP}$ 를 이용한 성능 평가, 분석 \\ 공현배 ${ }^{1} \cdot$ 조두진 $^{2 \dagger}$ \\ ${ }^{1} \mathrm{LIG}$ 넥스원(주) \\ (우 446-912 경기도 용인시 기흥구 마북동 148-1 \\ ${ }^{2}$ 아주대학교 물리학과 \\ 우 443-749 경기도 수원시 영통구 월드컵로 206}

(2013년 4월 18일 받음, 2013년 7월 19일 수정본 받음, 2013년 7월 22일 게재 확정)

본 논문에서는 두 매의 BD-2 렌즈와 비구면 회절 광학을 포함하는 F/1.2, 시야각 $15.2^{\circ}$ 와 8-14 $\mu \mathrm{m}$ 의 원적외선 파장대역을 가지 는 광학계를 설계하였다. 이 광학계는 uncooled camera에 사용될 수 있으며, 광학계의 분석은 BSP로 진행되었다. 회절광학은 주어진 두께를 가지는 물리적인 면으로 취급하였으며, 분석결과를 출사동공법과 같은 기존 방법들에 의한 것과 회절차수 합성법 에 의한 것과 비교하였다.

Keywords: 회절광학, 비구면광학, 적외선광학, 광시스템설계, 빔합성전파

OCIS codes: (220.0220) Optical design and fabrication; (220.3620) Lens system design; (050.1965) Diffractive lenses; (050.1970) diffractive optics

\section{I. 서 론}

현대의 고성능 렌즈설계에 있어서 회절렌즈의 사용은 필수 시 되고 있다. 이는 회절렌즈가 음의 고분산 특성을 가지므 로 적은 수의 렌즈로도 색수차를 보정하여 광학계의 성능을 향상 시킬 수 있기 때문이다 ${ }^{[1]}$. 다른 광학계와 비교하여 적외 선 광학계는 색수차의 영향을 덜 받지만, 높은 회절효율에 의해 회절 광학을 적용하기에 용이하므로 그 적용사례가 증
가하고 있다. 적외선의 특징을 이용하여 군사용, 자동차 산 업, 보안 분야 등의 상업적 영역에서 많은 관심을 끌고 있다. $\mathrm{CODE} \mathrm{V}$ 를 비롯한 광학설계 프로그램의 경우 회절광학이 포함된 광학계를 분석할 때 설계차수만을 설계 및 분석에 고 려한다. 이를 보완하기 위하여 개선된 방법으로 회절효율을 가중 치로 하여 설계차수 이외의 회절차수들을 합성하는 $\mathrm{SDOM}$ (회절차수 합성법, summation over diffraction orders method) 이 가장 널리 사용된다. zone의 수가 10 개 이상인 회절광학

${ }^{\dagger}$ E-mail: djcho@ajou.ac.kr

Color versions of one or more of the figures in this paper are available online. 
의 경우 이 방법은 좋은 결과를 줄 수 있다 ${ }^{[2]}$. Sauer ${ }^{[3]}$ 등은 윤대분할법을 제안하였는데, 이는 각 zone에 의한 PSF(Point Spread Function)를 가간섭적으로 합성하는 것으로서 본 논 문에서 비교한 출사동공법과 유사하다. 또한 $\mathrm{Zhang}^{[4]}$ 등은 각 파장에서 실제 위상함수를 고려하여 일반적인 광학설계 프 로그램에 적용할 수 있는 방법을 제안하고 SDOM과 비교한 바 있는데, 적용범위와 정확도 측면에서 제한을 가진다.

본 논문에서는 BSP(빔 합성 전파, Beam synthesis propagation) 를 이용하였는데, 이 방법은 광선추적법을 이용하여 회절효 과를 매우 정확하게 계산하며, 적용범위에 제한이 없는 것으 로 알려져 있다.

\section{II. 회절광학의 분석 방법들에 대한 간단한 소개}

$\mathrm{CODE} \mathrm{V}$ 의 BSP 분석은 파동방정식의 선형성에 기초를 두 고 있으며, 입력 광학장(Optical field) 또는 빔(Beam)을 많은 수의 빔릿(Beamlet)의 합성으로 근사한다. 광선추적법을 이 용하여 각각의 빔릿을 진행시킨 다음, 그들을 합성하여 진행 된 빔을 얻게 된다. 각 빔릿에는 기본광선(base ray)과 그 주 변의 광학장이 결부되어 있다 ${ }^{[5]}$.

$\mathrm{BSP}$ 와 유사한 방법들이 $\mathrm{ASAP}^{[6]}$ 과 같은 상용 분석 소프트 웨어에 사용되고 있지만, 렌즈설계 소프트웨어로서는 CODE $\mathrm{V}$ 가 유일하다. BSP에 의하여 얻어진 PSF로부터 MTF의 계 산은 2차원 푸리에변환으로 수행된다. 이때 수치적 오차를 최 소화하기 위하여 PSF의 그리드(grid) 크기와 전체크기를 유의 해서 설정하여야 한다.

대부분의 광학설계 프로그램에서는 일반 광소자의 경우와 마찬가지로 회절광학도 출사동공법을 적용한다. 물체로부터 출사동공까지 빛의 진행을 광선추적에 의하여 수행하고 빛 의 파동성은 출사동공에서 상면까지의 한 번의 회절전파로 취급한다. 이 때 회절광학의 경우 광선추적은 설계차수에 대 해서만 수행하기 때문에 여러 차수를 가지는 실제와 차이가 발생할 수 있다.

$\mathrm{SDOM}$ 에서는 여러 회절차수에 의한 세기(intensity)를 적절 히 합성함으로써 회절 광학의 특성을 해석한다. 설계차수 이 외의 상의 크기가 설계차수의 것과 크게 차이 나지 않을 경 우 그들의 PSF들을 그 회절효율을 가중치로 하여 적절히 합 성한 다음 푸리에변환에 의하여 MTF를 구하게 된다. 이 때 상들의 위치, 기준구면의 크기, PSF 그리드 크기 등을 유의해 서 맞추어야 한다. 이 방법은 윤대의 수가 10 또는 그 이상 인 회절광학에 대하여 적절하다. 윤대의 수가 많아지면 설계 차수 이외의 상의 크기가 상당히 커지게 되고 MTF는 설계 차수의 회절효율과 그 차수의 $\mathrm{MTF}$ 의 곱으로 주어진다 ${ }^{[7]}$.

\section{III. 광학계의 구성 및 설계}

본 논문에서 취급한 것은 그림 1 에 보인 2개의 BD-2 비구 면 렌즈와 실리콘 재질의 Window로 구성된 시야각 $15.2^{\circ}$, 중심파장 $10,500 \mathrm{~nm}$ 를 가지는 적외선 광학계이다 ${ }^{[8]}$.

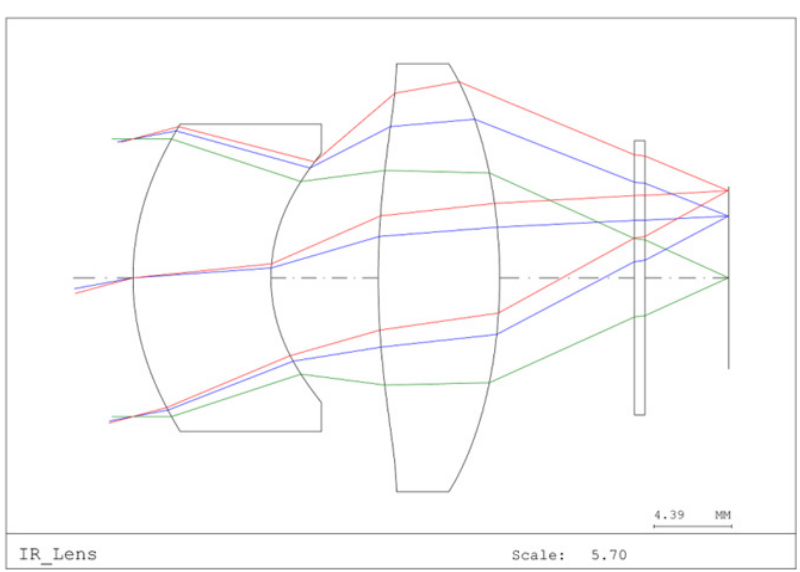

FIG. 1. Optical systems drawing with rays from three fields.

TABLE 1. Optical system data that involves two aspheric lenses. Surface 4 includes a diffractive surface with the aspheric

\begin{tabular}{c|c|c|c|c}
\hline \hline Surface number & Surface Type & $\begin{array}{c}\text { Radius } \\
(\mathrm{mm})\end{array}$ & $\begin{array}{c}\text { Thickness } \\
(\mathrm{mm})\end{array}$ & Material \\
\hline Object & Sphere & Infinity & Infinity & \\
\hline 1 & Asphere & 14.66 & 7.784 & BD-2 \\
\hline 2 & Asphere & 9.42 & 6.054 & \\
\hline 3 & Asphere & 49.36 & 6.845 & BD-2 \\
\hline 4 & Asphere-DOE & -31.63 & 7.606 & \\
\hline 5 & Sphere & Infinity & 0.591 & Silicon \\
\hline 6 & Sphere & Infinity & 4.730 & \\
\hline Image & Sphere & Infinity & 0 & \\
\hline
\end{tabular}

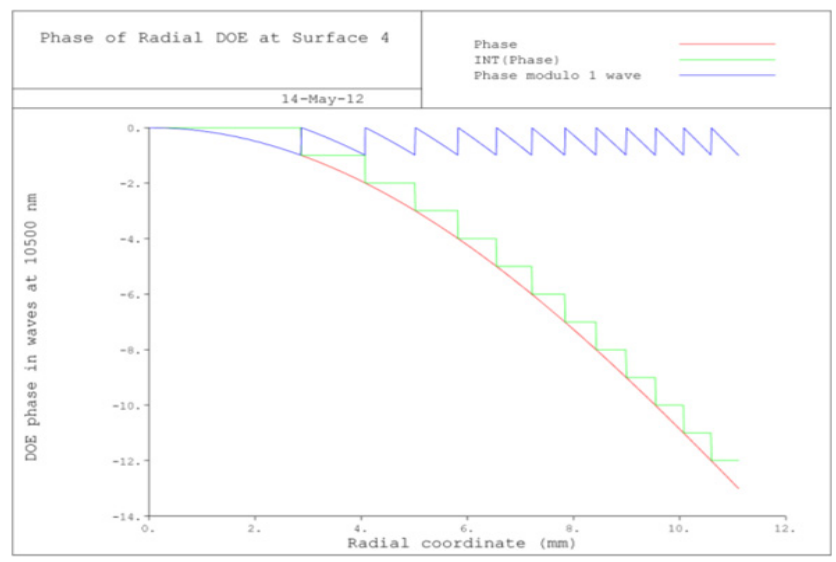

FIG. 2. DOE phase vs. Radial coordinate. Diffractive surface has 12 zones and $3329.9 \mathrm{~nm}$ depth.

최적화된 광학계의 면 속성은 표 1 과 같다. 파장대역은 8,000 $\mathrm{nm}, 10,000 \mathrm{~nm}, 10,500 \mathrm{~nm}, 12,000 \mathrm{~nm}, 14,000 \mathrm{~nm}$ 를 사용하 였으며, 중심파장에서의 굴절률은 2.6003 이다. 또한 네 번째 면의 회절면은 그림 2에 보인 바와 같이 $3329.9 \mathrm{~nm}$ 의 깊이 로 12 개의 윤대(zone)를 가짐으로 색수차를 효율적으로 감소 시켰다. 
광학계의 초기 설계는 식 (1), (2), (3)을 연립하여 각 렌즈 의 굴절능을 결정하였으며, 결정된 굴절능에 따라 렌즈제작 자의 공식을 이용하여 색수차 0 을 만족하는 각 면의 곡률을 지정하였다. $\Phi_{1}$ 은 첫 번째 렌즈의 굴절능이며, $\Phi_{2}$ 는 두 번째 렌즈의 굴절능, $\Phi_{3}$ 은 회절면의 굴절능이다. 광설계 소프트웨 어 상에서 비구면에 회절면이 적용되어도 실제 회절면의 두 께는 고려하지 않기 때문에 $\Phi_{2,3}$ 으로 표현하였다.

$$
\begin{aligned}
& \Phi_{1}+\Phi_{2,3}-t \Phi_{1} \Phi_{2,3}=\Phi_{\text {total }} \\
& \frac{\frac{1}{\Phi_{2,3}}\left(t-\frac{1}{\Phi_{1}}\right)}{t-\frac{1}{\Phi_{1}}-\frac{1}{\Phi_{2,3}}}=B F L \\
& \frac{y_{1}^{2} \Phi_{1}}{V_{1}}+\frac{y_{2}^{2} \Phi_{2}}{V_{2}}+\frac{y_{3}^{2} \Phi_{3}}{V_{3}}=0^{[9]}
\end{aligned}
$$

식 (1) (3)에서 $t$ 는 두 렌즈 사이의 거리이다.

회절면의 아베수는 $V_{d i f}=\frac{\lambda_{c}}{\lambda_{s}-\lambda_{l}}$ 으로 정의되며, $\Phi_{d i f}=$ $\frac{V_{d i f}}{V_{d i f}-V_{\text {ref }}} \Phi_{\text {total }}$ 의 식 ${ }^{[10]}$ 에 따라 회절면의 2차 계수를 얻어 내었으며, 최적화 과정에서 4차계수를 적용하였다.

광학계 설계 및 최적화는 $\mathrm{CODE} \mathrm{V}$ 와 $\mathrm{OSLO}^{[11]}$ 를 이용하여 진행하였으며, 광학계의 조리개는 외부 보호창에 붙는 잡티 들이 상에 주는 영향을 최소화하기 위하여 첫 번째 면에 위 치하였으며, 이는 첫 번째 렌즈의 크기를 줄여주는데도 기여 한다. 렌즈의 나머지 면들은 모두 비구면으로 구성되어 있으 며, 마지막 면은 Kinoform DOE가 비구면과 같이 위치되어 있다. $\mathrm{DOE}$ 는 12 개의 윤대수를 가지며, 효과적으로 광학계의 색수차를 줄여주는 역할을 하였다 ${ }^{[12]}$.

각 면에 대한 최적화는 $\mathrm{EFL}(=19 \mathrm{~mm}), \mathrm{BFL}(13.6 \mathrm{~mm})$, 전 장길이 $(32.6 \mathrm{~mm})$ 를 최종단계까지 구속조건으로 적용시켰으 며, 물체에서 가까운 면부터 순차적으로 진행하며 시야각을 점진적으로 증가시켰다. 조리개에 해당하는 첫 번째 비구면 은 3 차 코마, 비점수차와 왜곡수차에 영향을 주지 못하기 때 문에 구면수차에 대해서만 가중치를 적용시켰다. 또한 각 면 의 쟈이델 수차에 있어서 $\mathrm{CC}$ (Conic Constant)와 fourth-order coefficient는 동일한 효과를 가지기 때문에 동시에 적용시키 지 않았으며, 모두 $\mathrm{CC}$ 를 사용하였다. Window를 제외한 각 면에 $\mathrm{CC}$ 가 적용된 상태에서 8 차까지의 고차 비구면 계수들 을 변수로 지정하여 RMS Spot Size 방법을 이용하여 Spot size를 감소시켰으며, 각 비구면 계수들은 코마수차, 비점수 차, 페츠발 수차, 왜곡수차를 줄여주는데 기여하였다. 비구면 을 포함하는 광학설계는 일반 구면 광학설계에 비하여 많은 수의 광선을 필요로 하기 때문에 시야각은 $0,0.7,0.85,0.9$, 1 시야각을 사용하였다.

\section{BSP 및 MTF 분석}

그림 1 의 적외선 광학계에 대하여 $\mathrm{CODE} \mathrm{V}$ 를 이용하여 $\mathrm{BSP}$ 분석을 수행하였다. 분석 조건은 빔릿의 갯수를 결정하 며 입사동을 분할하는 광선의 수 70 개, 그리드 간격 $5.8 \mu \mathrm{m}$, 그리드 전체크기는 $1024 \times 1024$ 로 설정하였다. $\mathrm{CODE} \mathrm{V}$ 의 $\mathrm{BSP}$ 분석은 standard, enhanced, high의 3 가지 정확도 수준 설정 기능을 제공하는데 본 논문에서는 0.1 의 기본값을 가지 는 standard를 사용하였으며, 빔릿들이 얼마나 많은 수차를 축 적하고 있는지 확인하기 위한 임계값을 나타내는 $\mathrm{BWE}$ (Beamlet wavefront error)는 0.8 로 설정하였다.

광학계의 성능은 BSP 분석을 수행할 때 입사동을 분할하 는 광선의 수, 그리드 크기, 그리드 전체크기에 따라서 차이 를 보이기 때문에 타당성을 가지는 조건들로 BSP 분석을 해 야 한다. BSP 분석을 통해 광학계의 PSF를 푸리에변환하여 얻은 MTF를 그림 3에 보였으며, 회절광학이 포함된 광학계 의 특징인 낮은 공간주파수에서 MTF 저하 현상을 확인할 수 있다.

$\mathrm{CODE} \mathrm{V}$ 의 BSP 분석 후 MTF를 산출하기 위한 조건들의 타당성 확보를 위해 별도로 MATLAB의 FFT를 이용하여 MTF 를 산출하는 과정과 비교 검토하였다. $3 \mu \mathrm{m}$ 의 그리드 간격과 $1025 \times 1025$ 의 그리드 크기, BWE 0.4 의 조건으로 BSP 수행 후 얻은 PSF 데이터를 MATLAB을 이용하여 MTF로 변환 후 $\mathrm{CODE} \mathrm{V}$ 의 BSP 방법에 의한 MTF와 임의로 선택된 주 파수 $(12,24,36 \mathrm{lp} / \mathrm{mm})$ 에서 비교하였다. 모든 시야각에 대하 여 두 방법에 의한 MTF 값의 최대 차이는 $0.6 \%$ 였다.

그림 4 는 $3 \mu \mathrm{m}$ 의 그리드 간격과 $1025 \times 1025$ 의 그리드 크 기를 조건으로 BSP 수행 후 얻은 중심파장 $(10,500 \mathrm{~nm})$ 에서 의 PSF와 사용한 5 개의 파장을 동일한 가중치로 계산한 시 야각별 $\mathrm{PSF}$ 를 보였다. 그림을 보면 시야각이 증가할수록 $\mathrm{PSF}$ 의 크기가 커짐을 알 수 있는데, 이에 따라 그림 3에서 알 수 있듯이 최대 시야각에 근접할수록 MTF의 저하가 커 짐을 볼 수 있다. 또한 $\mathrm{CODE} \mathrm{V}$ 의 $\mathrm{BSP}$ 분석 시 설정한 5.8

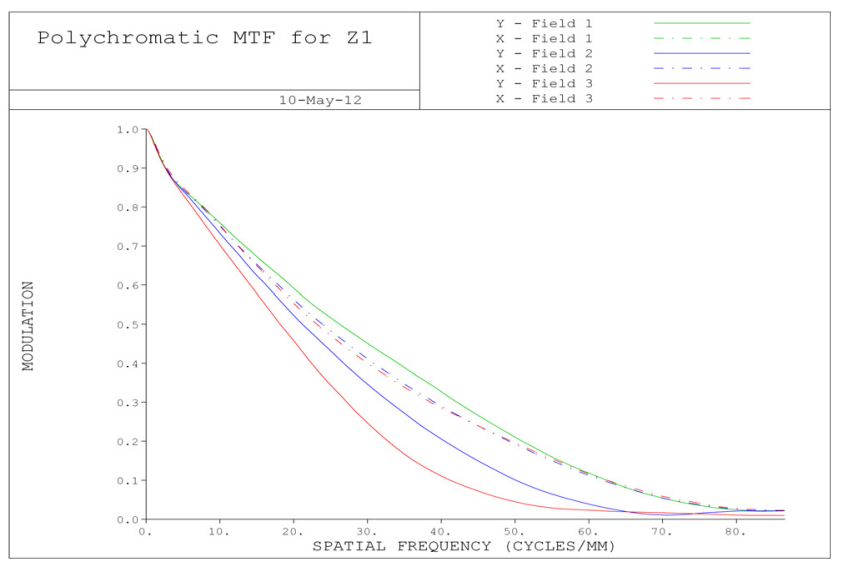

FIG. 3. MTF obtained by BSP as the field angle varies up to 15.2 degrees. Graph shape shows diffractive surface's characteristic at low spatial frequency. 

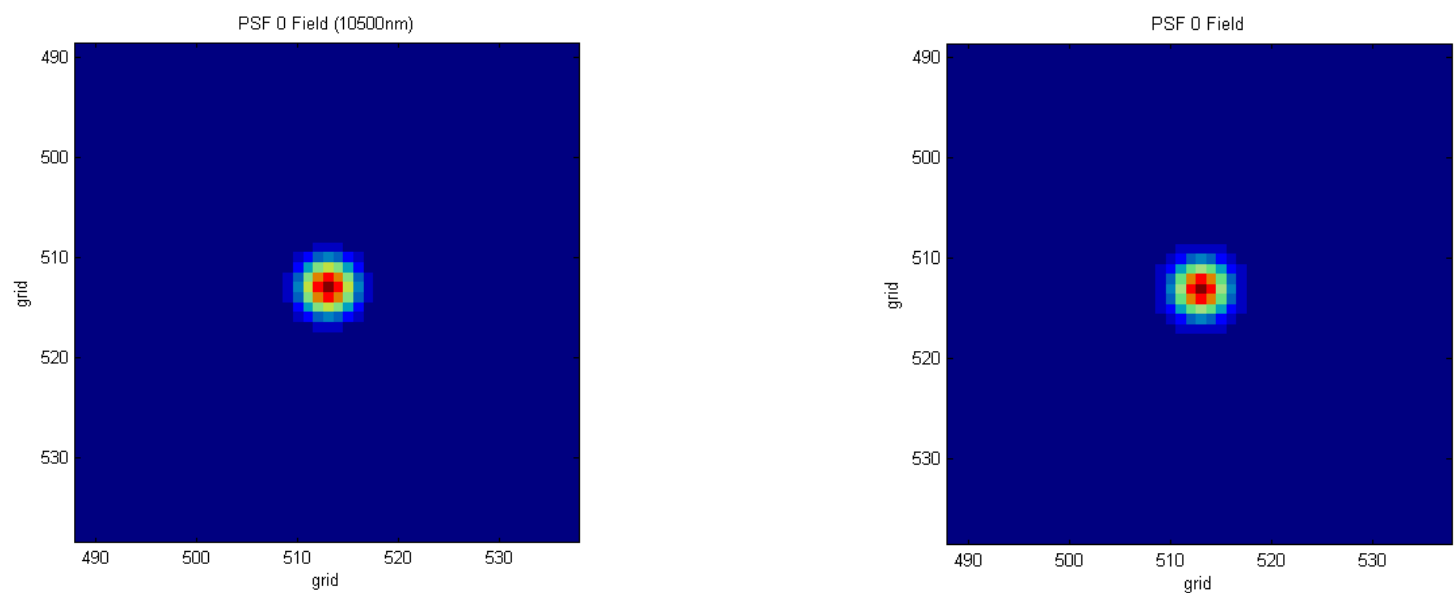

(a) on axis. Monochromatic (left); Polychromatic (right)
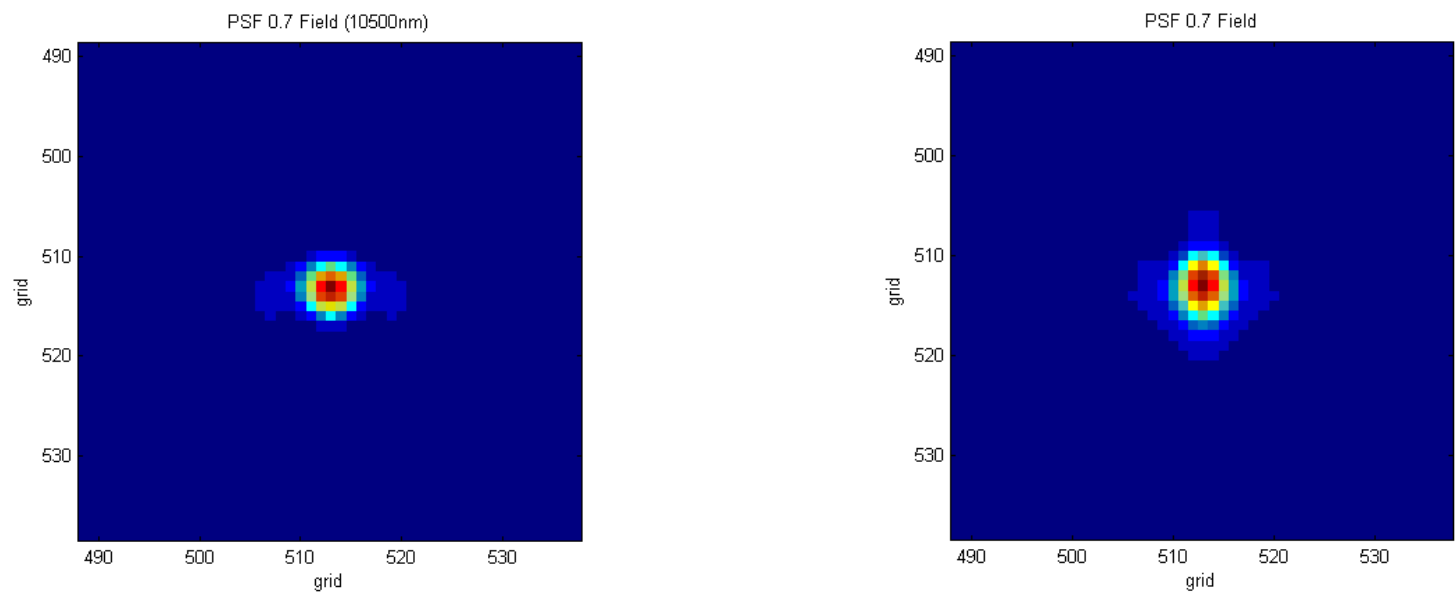

(b) at 0.7 field. Monochromatic (left); Polychromatic (right)
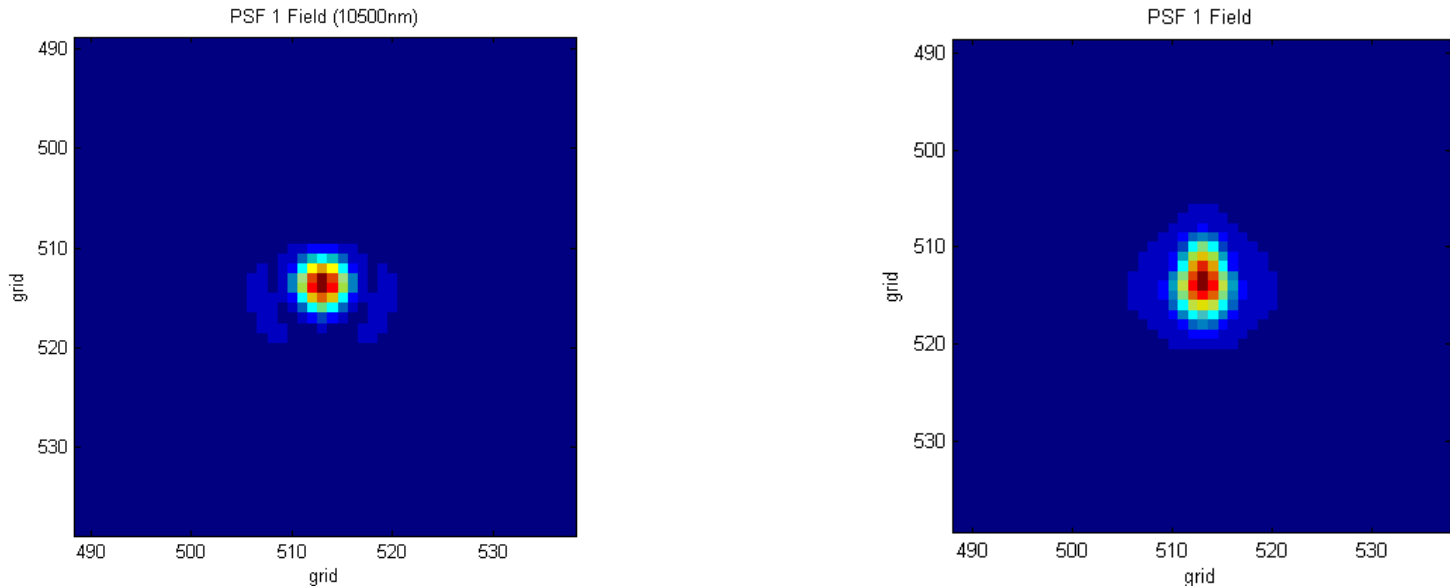

(c) at 1 field. Monochromatic (left); Polychromatic (right)

FIG. 4. Point Spread functions obtained by BSP.

$\mu \mathrm{m}, 1024 \times 1024$ 의 조건과 MATLAB의 $3 \mu \mathrm{m}, 1025 \times 1025$ 조건의 전체그리드 크기는 다르지만, $0.03 \mathrm{~mm}$ 정도로 형성 되는 PSF를 볼 수 있다.

그림 5는 BSP, DOE, UDS, SDOM 방법에 의한 MTF를 Radial, Tangential 별로 $40 \mathrm{lp} / \mathrm{mm}$ 까지 비교한 것이며, 0 필드 의 경우 Radial, Tangential MTF 값이 같기 때문에 Radial
$\mathrm{MTF}$ 값으로 표기하였다. 여기서 DOE와 UDS 방법은 단순 히 $\mathrm{CODE} \mathrm{V}$ 상에서 Quick MTF를 통해 얻은 것이며, UDS 방법은 CODE V의 UDS(User Define Surface) 기능을 이용 하여 회절면의 두께가 고려된 MTF를 나타낸다.

$\mathrm{MTF}$ 를 보면 알 수 있듯이 회절면의 두께와 회절차수를 모 두 고려하지 않은 $\mathrm{DOE}$ 방법은 다른 방법들에 비하여 가장 


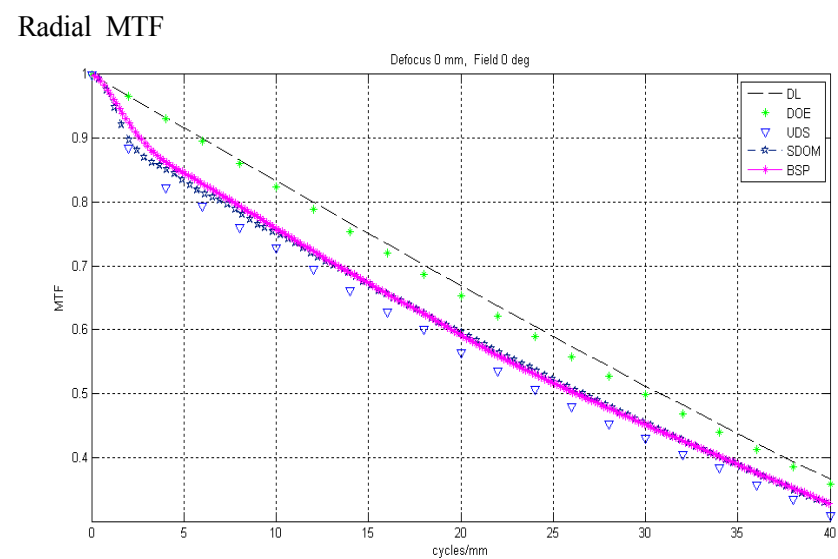

(a) radial MTF on axis

Radial MTF

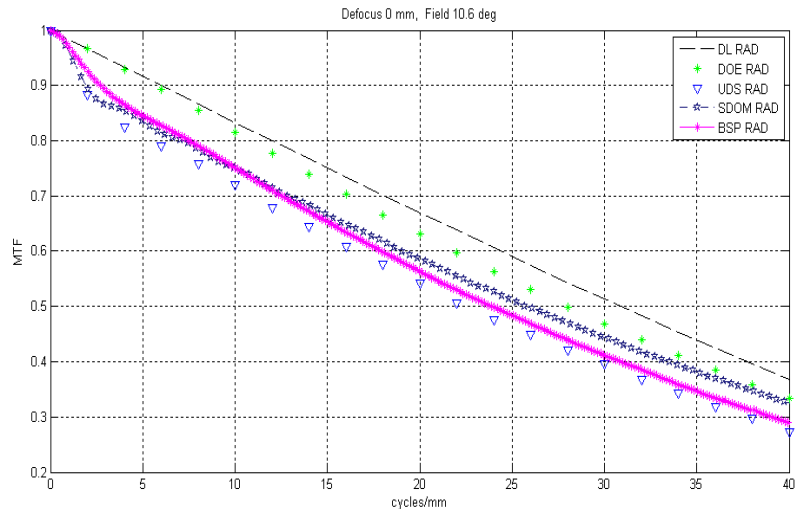

Tangential MTF

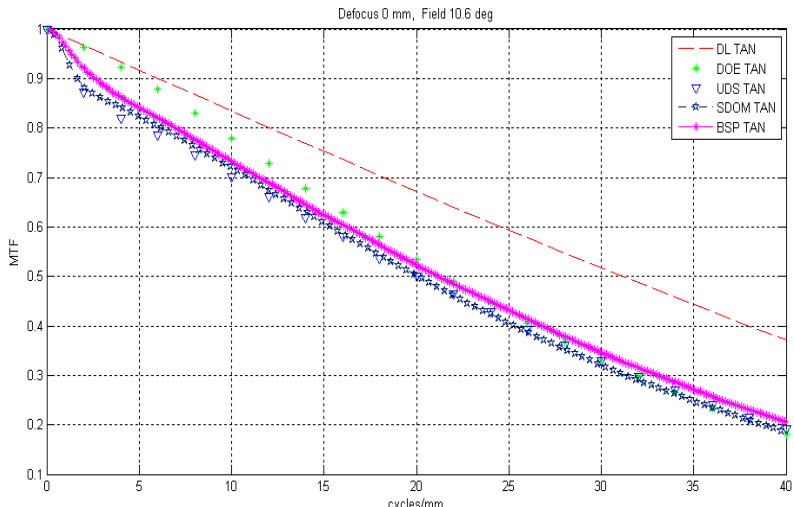

(b) radial and tangential MTF at 0.7 field

Radial MTF

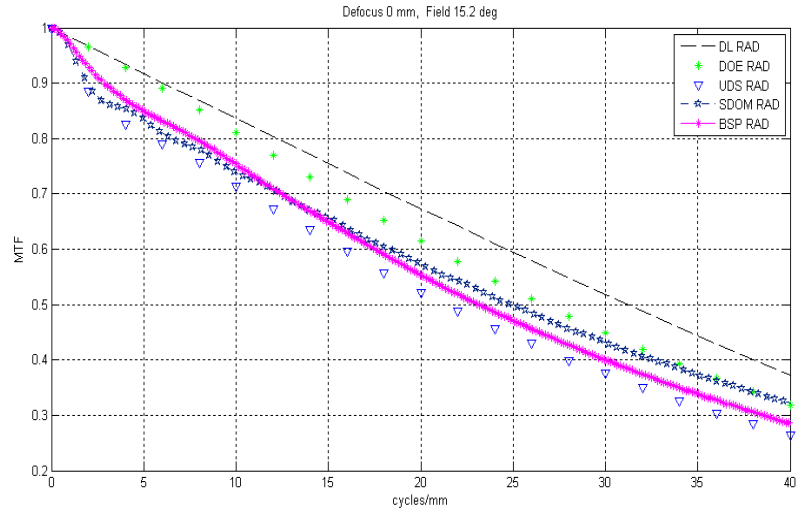

Tangential MTF

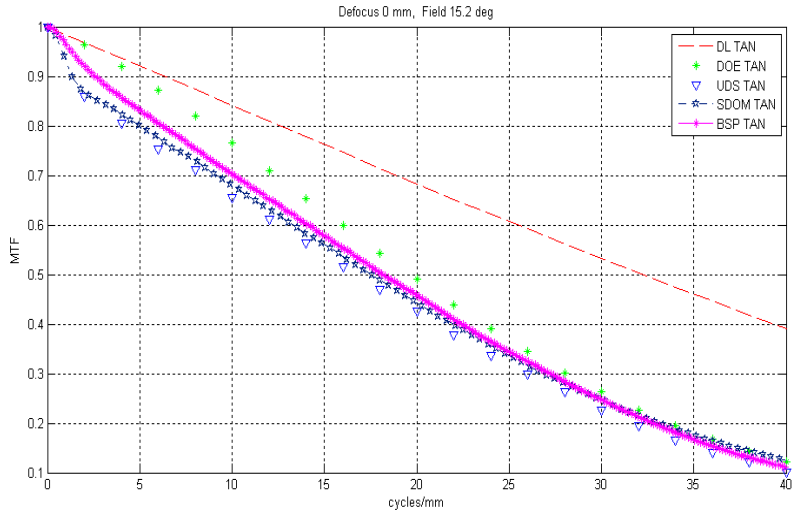

(c) radial and tangential MTF at 1 field

FIG. 5. MTF's obtained from BSP are compared to that of 5-orders method and exit-pupil methods.

높은 MTF 값을 가졌으나, 실제 회절광학을 포함하는 렌즈를 제작하여 $\mathrm{MTF}$ 로 성능 평가 시 발생하는 낮은 공간주파수 대에서의 일반적인 MTF 저하 현상은 보이지 않았다. 이는 $\mathrm{CODE} \mathrm{V}$ 에서 제공하는 일반적인 $\mathrm{DOE}$ 설계에 의한 $\mathrm{MTF}$ 평 가는 정확하지 않음을 보여준다. 이에 비해 회절면의 두께를 고려한 UDS 방법, 각 회절차수에서 빛의 세기를 합해 정규 화 시킨 $\mathrm{SDOM}$ 방법, $\mathrm{UDS}$ 를 적용시킨 상태에서 수행한 $\mathrm{BSP}$ 방법은 $\mathrm{DOE}$ 방법보다 낮은 $\mathrm{MTF}$ 성능을 보이지만 더욱 정
확하게 광학계를 분석하고 실제 제작 시에 발생하는 회절효 과를 분석했다고 할 수 있다. 4 번 면에 위치하는 회절렌즈의 윤대수가 극히 적었다면 SDOM 방법에 의한 MTF 값이 상 당히 높았을 것이라 예상되지만, 12 개의 윤대수를 가짐으로 $\mathrm{BSP}$ 와 $\mathrm{SDOM}$ 에 의한 결과는 큰 차이를 보이지 않았다. 하 지만 낮은 공간주파수 대에서 나타나는 일반적인 MTF 저하 현상 영역에서는 UDS와 $\mathrm{SDOM}$ 방법은 비슷한 $\mathrm{MTF}$ 값을 가짐에 비해 $\mathrm{BSP}$ 방법은 모든 시야각에서 상대적으로 높은 
MTF 성능을 보였다. 그리고 $0.7,1$ 시야각에서 공간주파수가 증가하였을 경우 $\mathrm{SDOM}$ 방법에 의한 radial MTF 값은 $\mathrm{DOE}$ 를 제외한 다른 방법에 의한 결과보다 상대적으로 높았는데, 이는 회절면의 두께를 무시하고 위상다항식으로 취급한 영 향이라고 생각된다.

각각의 방법에 대하여 임의로 선택한 공간주파수 $12(\mathrm{lp} / \mathrm{mm})$, $24(\mathrm{lp} / \mathrm{mm}), 36(\mathrm{lp} / \mathrm{mm})$ 에서의 MTF 값을 표 2에 보였다. BSP 방법을 중심으로 radial과 tangential의 합의 평균으로 $\mathrm{MTF}$ 성능을 비교하며 BSP와 DOE 방법을 비교하였을 때, 0시야 각에서는 $8.99 \%, 11.13 \%, 9.57 \%, 0.7$ 시야각에서는 $7.65 \%, 6.65 \%$,

TABLE 2. MTF values obtained by BSP are compared with that obtained by exit pupil methods(DOE, UDS) and a method which superposes diffraction orders(SDOM) at 12, 24, $36 \mathrm{lp} / \mathrm{mm}$

\begin{tabular}{|c|c|c|c|c|c|c|}
\hline \multirow{2}{*}{ DOE } & \multicolumn{2}{|c|}{$\operatorname{MTF}(12 \mathrm{lp} / \mathrm{mm})$} & \multicolumn{2}{|c|}{$\operatorname{MTF}(24$ lp/mm) } & \multicolumn{2}{|c|}{$\operatorname{MTF}(36 \mathrm{lp} / \mathrm{mm})$} \\
\hline & radial & tangential & radial & tangential & radial & tangential \\
\hline $\begin{array}{c}0 \text { Field } \\
\left(0^{\circ}\right)\end{array}$ & \multicolumn{2}{|c|}{0.788} & \multicolumn{2}{|c|}{0.589} & \multicolumn{2}{|c|}{0.412} \\
\hline $\begin{array}{c}0.7 \text { Field } \\
\left(10.6^{\circ}\right)\end{array}$ & 0.778 & 0.728 & 0.563 & 0.447 & 0.385 & 0.235 \\
\hline $\begin{array}{l}1 \text { Field } \\
\left(15.2^{\circ}\right)\end{array}$ & 0.770 & 0.710 & 0.543 & 0.391 & 0.367 & 0.167 \\
\hline \multirow{2}{*}{ UDS } & \multicolumn{2}{|c|}{$\operatorname{MTF}(12 \mathrm{lp} / \mathrm{mm})$} & \multicolumn{2}{|c|}{$\operatorname{MTF}(24$ lp/mm) } & \multicolumn{2}{|c|}{$\operatorname{MTF}(36 \mathrm{lp} / \mathrm{mm})$} \\
\hline & radial & tangential & radial & tangential & radial & tangential \\
\hline $\begin{array}{c}0 \text { Field } \\
\left(0^{\circ}\right)\end{array}$ & \multicolumn{2}{|c|}{0.695} & \multicolumn{2}{|c|}{0.507} & \multicolumn{2}{|c|}{0.356} \\
\hline $\begin{array}{c}0.7 \text { Field } \\
\left(10.6^{\circ}\right)\end{array}$ & 0.679 & 0.660 & 0.476 & 0.429 & 0.318 & 0.241 \\
\hline $\begin{array}{l}1 \text { Field } \\
\left(15.2^{\circ}\right)\end{array}$ & 0.672 & 0.611 & 0.457 & 0.337 & 0.303 & 0.140 \\
\hline
\end{tabular}

\begin{tabular}{c|c|c|c|c|c|c}
\hline \hline \multirow{2}{*}{ SDOM } & \multicolumn{2}{|c|}{ MTF(12 lp/mm) } & \multicolumn{2}{c|}{$\operatorname{MTF}(24 \mathrm{lp} / \mathrm{mm})$} & \multicolumn{2}{c|}{$\operatorname{MTF}(36 \mathrm{lp} / \mathrm{mm})$} \\
\cline { 2 - 7 } & radial & tangential & radial & tangential & radial & tangential \\
\hline $\begin{array}{c}\text { 0 Field } \\
\left(0^{\circ}\right)\end{array}$ & \multicolumn{2}{|c|}{0.718} & \multicolumn{2}{|c|}{0.537} & \multicolumn{2}{c}{0.375} \\
\hline $\begin{array}{c}0.7 \text { Field } \\
\left(10.6^{\circ}\right)\end{array}$ & 0.714 & 0.674 & 0.526 & 0.424 & 0.370 & 0.235 \\
\hline $\begin{array}{c}1 \text { Field } \\
\left(15.2^{\circ}\right)\end{array}$ & 0.708 & 0.632 & 0.512 & 0.357 & 0.362 & 0.164 \\
\hline
\end{tabular}

\begin{tabular}{c|c|c|c|c|c|c}
\hline \hline \multirow{2}{*}{ BSP } & \multicolumn{2}{|c|}{$\operatorname{MTF}(12 \mathrm{lp} / \mathrm{mm})$} & \multicolumn{2}{c|}{$\operatorname{MTF}(24 \mathrm{lp} / \mathrm{mm})$} & \multicolumn{2}{c}{$\operatorname{MTF}(36 \mathrm{lp} / \mathrm{mm})$} \\
\cline { 2 - 7 } & radial & tangential & radial & tangential & radial & tangential \\
\hline $\begin{array}{c}\text { 0 Field } \\
\left(0^{\circ}\right)\end{array}$ & \multicolumn{2}{|c|}{0.723} & \multicolumn{2}{|c|}{0.530} & \multicolumn{2}{c}{0.376} \\
\hline $\begin{array}{c}0.7 \text { Field } \\
\left(10.6^{\circ}\right)\end{array}$ & 0.710 & 0.689 & 0.498 & 0.449 & 0.334 & 0.257 \\
\hline $\begin{array}{c}\text { 1 Field } \\
\left(15.2^{\circ}\right)\end{array}$ & 0.709 & 0.652 & 0.486 & 0.364 & 0.327 & 0.153 \\
\hline
\end{tabular}

$4.91 \%, 1$ 시야각에서는 $8.74 \%, 9.88 \%, 11.25 \%$ 이다. BSP와 $\mathrm{UDS}$ 를 비교했을 때의 0 시야각에서 $\mathrm{MTF}$ 의 차이는 $3.87 \%$, $4.34 \%, 5.32 \%, 0.7$ 시야각에서는 $4.29 \%, 4.44 \%, 5.41 \%, 1$ 시 야각에서는 $5.73 \%, 6.59 \%, 7.71 \%$ 이다. $\mathrm{BSP}$ 와 $\mathrm{SDOM}$ 에 대하 여 비교하여 보면 0 시야각에서 $0.69 \%, 1.32 \%, 0.27 \%, 0.7$ 시야각에서는 $0.78 \%, 0.31 \%, 2.36 \%$ 이며 1 시야각에서는 $1.54 \%$, $2.24 \%, 9.58 \%$ 의 차이를 보인다. 가장 큰 차이를 보인 것은 1 시야각의 $36 \mathrm{lp} / \mathrm{mm}$ 에서 $\mathrm{BSP}$ 와 $\mathrm{DOE}$ 방법이며 $11.25 \%$ 의 차 이를 보였다.

\section{V. 결 론}

본 논문에서는 2개의 BD-2 렌즈와 Window로 구성된 시야 각 $15.2^{\circ}, \mathrm{F} / 1.2$ 의 회절면을 포함하는 적외선 광학계를 광학 설계 프로그램인 $\mathrm{CODE} \mathrm{V}$ 와 $\mathrm{OSLO}$ 를 이용하여 설계하였으 며 두 번째 렌즈에 위치한 12개의 zone을 가진 회절면은 비 구면 기판위에 입혀진 것으로 블레이즈 두께를 갖는 물리적 인 면으로 취급하였다. 회절효과를 매우 정확하게 분석하는 BSP 방법을 이용하여 광학계의 성능을 $\mathrm{DOE}, \mathrm{UDS}$ 및 $\mathrm{SDOM}$ 에 의한 $\mathrm{MTF}$ 와 비교하고 분석하였다.

radial과 tangential MTF의 합의 평균으로 각 시야각에 대 하여 임의로 선택한 $12,24,36 \mathrm{lp} / \mathrm{mm}$ 에서 각각의 방법에 의 한 MTF를 BSP 방법을 중심으로 비교하였을 때, 회절면의 두께, 회절차수 등을 고려하지 않은 일반적인 분석방법인 $\mathrm{DOE}$ 방법이 가장 높은 MTF 값을 보였지만, 회절광학을 포 함한 광학계에서 나타나는 낮은 공간주파수 대역에서 일반 적인 MTF 저하 현상도 보이지 않았다. 이에 비해 회절면의 두께만을 고려한 UDS 방법은 상대적으로 가장 낮은 MTF 성능을 보였으며, 회절면의 윤대수가 12 개라는 점에 기인하 여 $\mathrm{BSP}$ 와 $\mathrm{SDOM}$ 방법은 큰 차이를 보이지 않았다. $\mathrm{SDOM}$ 방법의 $0.7,1$ 시야각의 경우 공간주파수가 증가하였을 때 radial MTF 값이 다른 방법에 의한 결과보다 상대적으로 높 았는데 이는 SDOM 방법이 회절면의 두께를 고려하지 않으 며, 위상다항식으로 취급한 영향이라 생각된다.

$\mathrm{DOE}$ 와 BSP 방법과의 MTF 성능 차이는 시야각의 증가함 에 따라 더욱 커졌으며 1 시야각의 $36 \mathrm{lp} / \mathrm{mm}$ 에서 $11.25 \%$ 로 가장 큰 차이를 보였다. 이러한 결과는 $\mathrm{DOE}$ 방법에 의존하여 광학계의 성능을 평가하고 제작 및 생산했을 때 실제 광학계 의 성능과 큰 차이를 보일 수 있음을 의미한다.

추후 $\mathrm{BSP}$ 를 바탕으로 회절광학의 최적화와 zone의 Back $\mathrm{Cut}$ Edge를 적용시키는 연구를 통해 보다 효율적이고 정확 한 회절광학 광학계의 분석이 가능하리라 기대된다.

\section{감사의 글}

이 논문은 아주대학교 물리학과, LIG 넥스원 탐색기/광학 연구센터의 지원으로 수행되었습니다. 


\section{References}

1. D. C. O'Shea, T. J. Suleski, A. D. Kathman, and D. W. Prather, Diffractive Optics : Design, Fabrication, and Test (SPIE Press, Bellingham, USA, 2004).

2. M. D. Thorpe, R. P. Jonas, and S. Szapiel, "Modeling of polychromatic MTF losses due to secondary effects in diffractive lenses," Proc. SPIE 6667, 66670E1-66670E12 (2007).

3. H. Sauer, P. Chavel, and G. Erdei, "Diffractive optical elements in hybrid lenses: modeling and design by zone decomposition," Appl. Opt. 38, 6482-6486 (1999).

4. H. Zhang, H. Liu, Z. Lu, and H. Zhang, "Modified phase function model for kinoform lenses," Appl. Opt. 47, 4055-4060 (2008).

5. CODE V, Optical Research Associates, Inc., California, USA.
6. ASAP, Breault Research Associates, Inc., Arizona, USA.

7. H. S. Lee, "Lens design involving diffractive optics and performance evaluation and analysis using Beam Synthesis Propagation." M.S. Thesis, Ajou University (2010).

8. G. Curatu, "Design and fabrication of low-cost thermal imaging optics using precision chalcogenide glass molding," Proc. SPIE 7060, 706008-1 (2008).

9. J. M. Geary, Introduction to Lens Design (Willmann-Bell, Inc. Virginia, USA, 2002) p. 205.

10. H. S. Lee, C. Seog Rim, and J. H. Jo, "The comparison and the analysis of the optical performances between the single and the symmetrical double DOE lenses," Korean J. Opt. Photon. (Hankook Kwanghak Hoeji) 13, 258-265 (2002).

11. OSLO, Lambda Research Corporation, Littleton, MA, USA.

12. H. B. Kong, "Design and analysis of infrared diffractive optical systems using beam synthesis propagation," M.S. Thesis, Ajou University (2012). 